\title{
Episomal and integrated human papillomavirus in cervical neoplasia shown by non-isotopic in situ hybridisation
}

\author{
K Cooper, C S Herrington, J E Stickland, M F Evans, J O’D McGee
}

\begin{abstract}
It was postulated that non-isotopic in situ hybridisation (NISH) signal types 1-3 for human papillomavirus in cervical biopsy specimens represent episomal or integrated virus. The aim of this study was to validate this hypothesis by independent molecular techniques. Fresh cervical intraepithelial neoplasia (CIN) and squamous cell cancer (SCC) tissue were examined for NISH signal pattern by hybridising with digoxigenin labelled HPV 16. DNA was extracted from the same samples and analysed by restriction endonuclease digestion and Southern blotting to determine the physical state of the viral genome. Six CIN biopsy specimens showed a type 1 NISH signal for HPV 16. On Southern analysis these biopsy specimens contained only episomal HPV 16. Three SCC with a type 2 NISH signal contained integrated HPV 16 by Southern analysis. Two specimens, a CIN 3 and an SCC with a type 3 NISH signal for HPV 16, showed the presence of both episomal and integrated HPV 16 with conventional Southern analysis and two dimensional gel electrophoresis.

These results show that episomal HPV can be reliably determined by NISH type 1 signal, integrated HPV by type 2 , and a combination of both episomal and integrated HPV, by a type 3 signal in archival paraffin wax embedded cervical biopsy specimens. This will add another variable to the epidemiological studies of HPV infection. In particular, it will now allow retrospective studies to be done to define the role of episomal and integrated HPV in the evolution of cervical intraepithelial neoplasia and other cervical disease associated with this virus.
\end{abstract}

University of Oxford, Nuffield Department of Pathology, John Radclifie Hospital, Oxford OX3 9DU K Cooper C S Herrington

J E Stickland

M F Evans

J O'D McGee

Correspondence to:

Professor J O'D McGee

Accepted for publication 4 September 1991

Certain human papillomavirus (HPV) types, particularly HPV 16 and 18, and to a lesser extent $31,33,35,45,51$, and $52,{ }^{1}$ have been associated with cervical intraepithelial neoplasia and invasive cancer. Although epidemiological studies have produced conflicting results, ${ }^{2}$ there is experimental evidence to support a pathogenetic role for HPV in cervical preneoplasia and cancer. ${ }^{3}$ The part played by integration of HPV DNA into the human genome has attracted increasing interest. HPV DNA is integrated into the host genome in immortalised human keratinocytes, ${ }^{45}$ cell lines derived from cervical cancers, ${ }^{67}$ cervical intraepithelial neoplasia (CIN), ${ }^{8-12}$ and squamous cell cancers (SCC).$^{810-14}$ Integration disrupts the E1/E2 open reading frames with consequent derepression of viral gene expression and subsequent overexpression of the E6 and E7 ORFs. ${ }^{15}$ Clinical studies that correlate E6 and E7 overexpression with poor prognosis in $\mathrm{CIN}^{16}$ lend support to the potential importance of detection of HPV integration in cervical neoplasia.

Viral integration can be shown in several ways in clinical material. All require destruction of tissue morphology, however, and are technically time consuming; restriction digestion and Southern blot analysis provide indirect evidence, while the cloning of virushost cell junction fragments is definitive. ${ }^{13}$ Direct morphological evidence of viral integration is provided by in situ hybridisation on metaphase chromosomes derived from cervical carcinoma cells ${ }^{17}$ but this requires cell culture. None of these methods is routinely applicable to small clinical biopsy specimens. Recently it was shown that HPV DNA is present in three morphologically distinct forms in the nuclei of cervical preneoplasia and neoplasia by nonisotopic in situ hybridisation (NISH). ${ }^{18}{ }^{19}$ These forms are referred to as NISH signals types 1,2 , and 3. A type 1 signal is diffuse and present throughout the nucleus; a type 2 signal is punctate; and type 3 is a combination of type 1 and 2 . It was postulated that a type 1 signal represents episomal virus, type 2 integrated virus, and type 3 a combination of both. ${ }^{1819}$ To examine this hypothesis further, we have now examined fresh CIN and SCC tissue for an NISH signal pattern, extracted DNA from the same biopsy specimens and analysed them by Southern blotting to determine the physical state of the viral genome.

\section{Methods}

Cervical biopsy specimens came from patients with HPV infection, CIN, or SCC, as defined by conventional morphological criteria. ${ }^{20}$ Samples were snap frozen in liquid nitrogen and stored at $-70^{\circ} \mathrm{C}$ until used. The CaSki, HeLa, and SiHa cell lines (ATCC, USA) derived from cervical carcinoma were grown and prepared as previously described. ${ }^{21}$ 
Frozen sections ( $5 \mu \mathrm{m}$ ) were cut from biopsy specimens and treated as for cultured cell lines by fixation in methanol-acetic acid (3:1 v/v), $4 \%(\mathrm{w} / \mathrm{v})$ paraformaldehyde, and washed in phosphate buffered saline (PBS) $(10 \mathrm{mM}$ phosphate, $150 \mathrm{mM} \mathrm{NaCl}, \mathrm{pH} 7 \cdot 2$ ) containing $0.2 \%$ glycine. ${ }^{22}$ Slides were washed in PBS, air dried, and stored at $-70^{\circ} \mathrm{C}$. One section was stained with haematoxylin and eosin, and the remainder were analysed by NISH.

\section{NISH}

After unmasking with proteinase $\mathrm{K}$ (Boehringer-Mannheim, Germany) at concentrations ranging from $0 \cdot 1 \mu \mathrm{g} / \mathrm{ml}$ to $2 \mu \mathrm{g} / \mathrm{ml}$ (depending on the batch of enzyme and the sample) for 15 minutes at $37^{\circ} \mathrm{C}$, NISH was carried out as previously described using nick-translated digoxigenin labelled HPV 16 probes $^{21}$ and a three step antibody-avidin detection method with aminoethylcarbazole as the final substrate. ${ }^{22}$ An HPV 16 positive control biopsy specimen was included in each experiment and six other digoxigenin labelled HPV probes (HPV 6, 11 18, 31, 33, 35) ${ }^{18} 1921$ were used on each biopsy specimen as negative controls.

\section{DNA EXTRACTION}

From a set of 53 biopsy specimens, 11 containing HPV 16 detected by NISH were selected. DNA was extracted and analysed by restriction digestion and Southern blotting. HeLa cell DNA (which contains integrated HPV 18) ${ }^{23}$ and breast tumour DNA were used as negative controls. CaSki and $\mathrm{SiHa}$ cells contain integrated HPV 16 in $300-500^{23}$ and one to two copies, ${ }^{24}$ respectively, and were used as positive controls.

DNA was extracted by incubation in $10 \mathrm{mmol} / 1$ TRIS-HCl, pH $7 \cdot 8,150 \mathrm{mmol} / 1$ $\mathrm{NaCl}, 10 \mathrm{mmol} / 1 \mathrm{EDTA}, 0.6 \%$ (w/v) sodium dodecyl sulphate (SDS), and $100 \mu \mathrm{g} / \mathrm{ml}$ proteinase $\mathrm{K}$ (Boehringer-Mannheim, Germany) at $37^{\circ} \mathrm{C}$ overnight; it was then extracted once with phenol, twice with phenol-choloroform, and twice with choroform-isoamyl alcohol (24:1). DNA was precipitated with ethanol and resuspended in TRIS-EDTA buffer $(10 \mathrm{mmol} / 1$ TRIS- $\mathrm{HCl}$, pH8, $1 \mathrm{mmol} / 1$ EDTA) ${ }^{25}$ The yield of DNA ranged from 60 to $500 \mu \mathrm{g}$ per biopsy specimen.

SOUTHERN BLOT ANALYSIS

This was performed according to standard

NISH signal type and physical state of HPV in CIN and SCC

\begin{tabular}{clll}
\hline Case number & Clinical diagnosis & NISH signal type & Physical state of virus* \\
\hline 1 & CIN 2 and HPV & 1 & Episomal \\
2 & CIN 3 and HPV & 1 & Episomal \\
5 & CIN 3 and HPV & 1 & Episomal \\
8 & HPV & 1 & Episomal \\
10 & HPV & 1 & Episomal \\
12 & CIN 3 and HPV & 3 & Episomal and integrated \\
13 & CIN 2 and HPV & 1 & Integrated \\
14 & SCC & 2 & Episomal and integrated \\
121 & SCC & 3 & Integrated \\
135 & SCC & 2 & Integrated \\
137 & SCC & 2 & \\
\hline
\end{tabular}

HPV = human papillomavirus; $\mathrm{CIN}=$ cervical intraepithelial neoplasia; $\mathrm{SCC}=$ squamous cell cancer.

^Determined by restriction enzyme digestion and Southern blotting. techniques. ${ }^{25} 26$ Genomic DNA $(10 \mu \mathrm{g})$ was digested with three restriction endonucleuses: BamHI, which cuts wild-type HPV 16 once at position 6150 in the conserved late region, and $H$ indIII and $X h o I$, which cut tumour DNA but not HPV 16. After electrophoresis on $0.8 \%$ $(w / v)$ agarose gels the digested DNA was transferred to Hybond $\mathrm{N}$ (Amersham) nylon membrane and cross linked with ultraviolet light using a Stratalinker (Stratagene).

HPV 16 genomic DNA was excised from the vector pAT $153^{27}$ and isolated on DEAE NA45 paper. ${ }^{25}$ The HPV 16 insert was labelled with $\alpha-{ }^{32} \mathrm{P}-\mathrm{dCTP}$ by random primer directed synthesis according to the manufacturer's instructions (Boerhinger-Mannheim, Germany) and residual unincorporated nucleotides removed on a Sephadex G-50 column. A specific activity of $1.5 \times 10^{8} \mathrm{dpm} / \mu \mathrm{g}$ DNA was typically obtained.

Southern blots were prehybridised for two hours at $42^{\circ} \mathrm{C}$ in prehybridisation solution containing $50 \%$ deionised formamide, $1 \times$ Denhardt's solution $(100 \times$ Denhardt's $=2 \% \quad(\mathrm{w} / \mathrm{v})$ bovine serum albumin, $2 \%$ (w/v) Ficoll, $2 \%$ (w/v) polyvinylpyrrolidone), $5 \times$ SSPE $(20 \times$ SSPE $=3.6 \mathrm{M} \mathrm{NaCl}, 0.2 \mathrm{M}$ sodium phosphate, $0 \cdot 2 \mathrm{M}$ EDTA, pH 7.5), $1 \%$ $(\mathrm{w} / \mathrm{v})$ sodium dodecyl sulphate (SDS) and $0.2 \mathrm{mg} / \mathrm{ml}$ of denatured sheared herring sperm DNA. Filters were hybridised overnight at $42^{\circ} \mathrm{C}$ in prehybridised solution to which $5 \%$ $(w / v)$ dextran sulphate and denatured labelled probe $\left(1-2 \times 10^{6} \mathrm{cpm} / \mathrm{ml}\right)$ were added. After hybridisation, washing was carried out in two changes of $2 \times$ SSPE containing $0.2 \%$ SDS for five minutes at room temperature followed by one of $0.2 \times \mathrm{SSPE} / 0.2 \% \mathrm{SDS}$ at $65^{\circ} \mathrm{C}$ for 20 minutes and signal detected by autoradiography for three to 12 days at $-70^{\circ} \mathrm{C}$ using Fuji RX film. These conditions represent calculated hybridisation and washing stringencies of Tm$20^{\circ} \mathrm{C}$ and $\mathrm{Tm}-10^{\circ} \mathrm{C}$, respectively. HindIII digested lambda phage was used as a molecular marker in all electrophoretic agarose gels.

Two cases in which complex restriction patterns were obtained were reanalysed by two-dimensional gel electrophoresis to clarify the physical states of the HPV DNA. ${ }^{28}$ HindIII digested DNA $(10 \mu \mathrm{g})$ was run on a $0.4 \%$ agarose gel at $25 \mathrm{~V}$ for 14 hours. The lane was then excised and recast with a $0.8 \%$ electrophoretic agarose gel and run at $90^{\circ}$ to the original direction for five to six hours at $60 \mathrm{~V}$.

\section{Results}

From 53 fresh frozen biopsy specimens, 11 were selected for further study. The criteria for inclusion were that on frozen sections a type 1 , 2 , or 3 NISH signal was evident and that there was sufficient tissue for DNA extraction and characterisation by restriction enzyme digestion and Southern blotting.

Four biopsy specimens showing morphological features of CIN 2 or 3 with coincident wart virus infection and two with wart virus infection changes only gave a type 1 diffuse NISH signal pattern ${ }^{18}$ (table) (fig 1A). Three SCC gave a punctuate/dot type 2 NISH 
Figure 1

Photomicrographs of HPV

$16 D N A$ shown by non-

isotopic in situ

hybridisation (NISH).

(A) NISH signal type 1. $A$ diffuse intranuclear

pattern of staining is noted

in these squamous

epithelial cells. (B)

Punctuate discrete dots are present in the

haematoxylin stained

squamous cell cancer nucle

with a clean background.

This is a type 2 NISH

signal. Type 3 NISH

signal is present in

adjacent nuclei in CIN3

$H P V(C)$, and squamous cell cancer $(D)$.
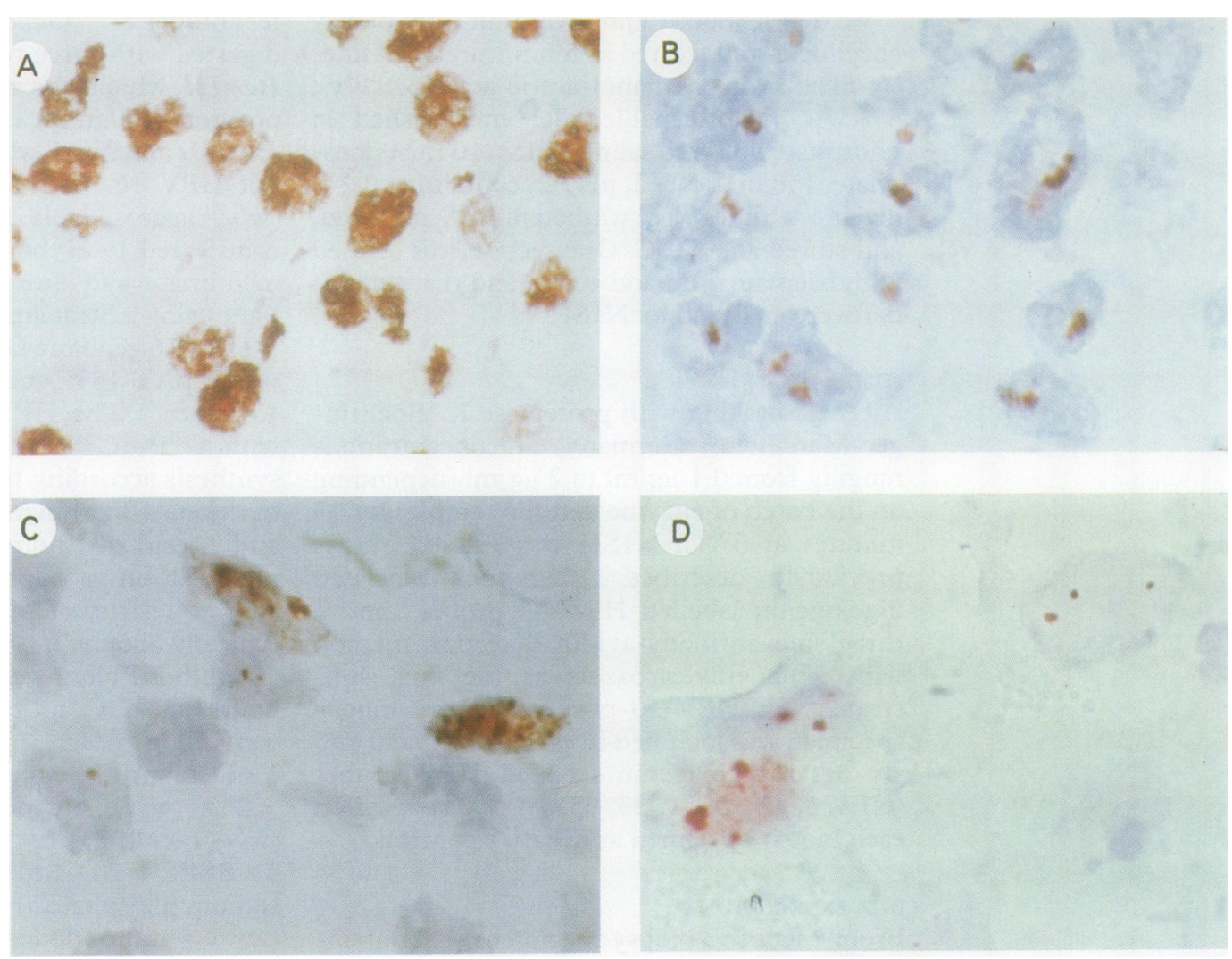

signal in most of the tumour cells, with about one to three signals/cell ${ }^{19}$ (fig 1B). A type 3 signal was present in a CIN 3 lesion showing coincident morphological evidence of wart virus infection (fig 1C) and in an SCC where most of the tumour cells had a type 2 signal and isolated scattered cells a type 1 signal ${ }^{18}{ }^{19}$ (fig 1D).

A type 2 NISH signal was obtained by NISH using HPV 16 in CaSki cells (three to 20 dots per cell) ${ }^{22}$ and SiHa cells (one to two dots per cell).$^{29}$ Both these cell lines contain integrated HPV $16^{2324}$ and were used as positive controls for Southern blot analysis. HeLa cells contain integrated HPV $18^{23}$ and gave no signal with the HPV 16 probe. None of the biopsy specimens studied here reacted with HPV 6, 11, 18, 31, 33 or 35 on NISH.

\section{NISH TYPE 1 SIGNAL AND EPISOMAL HPV}

The methods used for determining the physical state of HPV DNA in fresh frozen cervical material were adapted from those described by Durst. ${ }^{28}$ The detection of episomal viral DNA is based on the fact that the HPV 16 genome is a double stranded, circular DNA molecule 7.9 kilobases long. This form of the virus (Form 1) is supercoiled and has the greatest electrophoretic mobility in agarose gels with an apparent molecular weight of about 4.4 kilobases. After DNA extraction a nick may be introduced into one of the supercoiled strands. This produces the nicked/relaxed form (Form 2 ;"open" circular), which has a lower electrophoretic mobility than Form 1. Digestion with a restriction endonuclease that cleaves the viral genome once-for example BamHI, generates the linearised form of the viral DNA (Form 3); this produces a band at a position of 7.9 kilobases on agarose gels with an electrophoretic mobility intermediate between forms 1 and $2 .^{28}$

Using these principles, the episomal state of HPV DNA was clearly shown in cases $1,2,5,8$, 10 and 13 (table) all of which showed type 1 NISH signal (fig 1A). The episomal bands noted on the HindIII and XhoI digested DNA lanes are identical with those seen with the uncut genomic DNA because these enzymes do not cut the HPV 16 genome. After digestion with BamHI (which cleaves HPV 16 only once), both forms 1 and 2 of the episomal viral DNA are linearised to 7.9 kilobases; the absence of additional off-sized bands in this lane excludes the possibility of integrated viral genome in these biopsy specimens (fig 2).

The high molecular weight bands in cases 5 and 13 most likely represent oligomeric circular DNA arranged as catanates. The distinct linearisation of this form to 7.9 kilobases with BamHI digestion in all six cases in this study, as well the absence of noticeably different band sizes after HindIII and XhoI digestion, confirms that these biopsy specimens with a type 1 NISH signal contain only episomal HPV 16. The 7.9 kilobase bands in the uncut, HindIII and $X h o I$ digested lanes is probably as result of linearisation of circular HPV 16 following DNA extraction.

NISH TYPE 2 SIGNAL AND INTEGRATED HPV This was shown by the changed migration, when compared with the undigested sample, of extracted DNA after digestion with two different restriction endonucleases which have no cleavage sites in the HPV 16 genome. HPV 


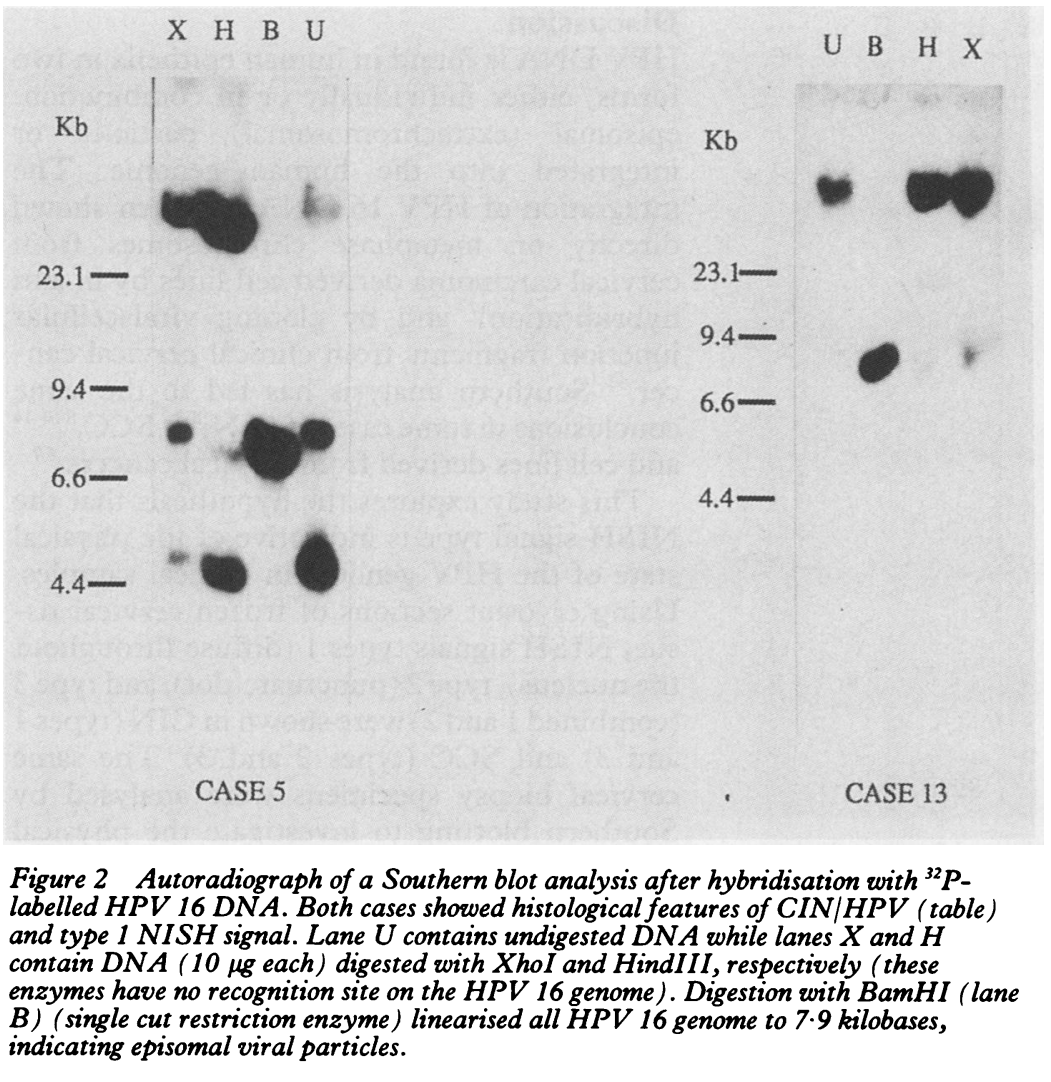

$\begin{array}{llll}X & \mathrm{H} & \mathrm{B} & \mathrm{U}\end{array}$

$\mathrm{Kb}$
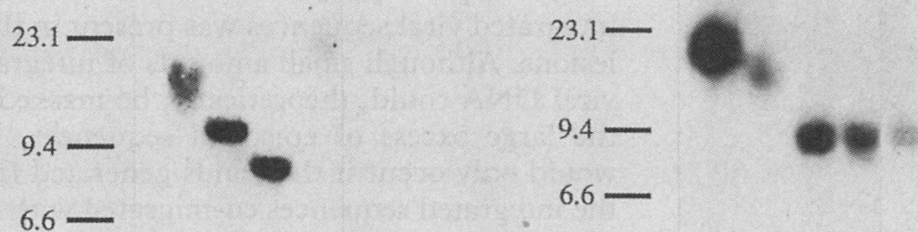

$4.4-$
$\mathrm{Kb}$

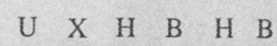

$* *$

$4.4-$

an:

cases of cervical SCC with a type 2 NISH signal (fig 1B).

Further confirmation that this signal represents HPV integration is provided by the presence of off-sized bands after BamHI digestion in addition to the linearised form of HPV DNA (fig 3). The variable size of these additional bands with BamHI digestion, as well as their absence after HindIII and XhoI digestion, imply that they represent covalently bound virus/cell junction fragments as a result of integration of HPV 16 into the human genome. The size of these additional bands is determined by the relative locations of $\mathrm{BamHI}$ sites within the HPV 16 DNA and the flanking host cell DNA (see Discussion).

The additional HindIII band in case 135 (illustrated with two different exposure times) may be the result of the presence of a variant HPV 16 DNA molecule which has gained a HindIII restriction site, or the presence of rearranged/amplified HPV 16 DNA molecules in this cancer ${ }^{30}$ (see Discussion).

The same restrictions patterns were found by Southern blot analysis of $\mathrm{CaSki}$ and $\mathrm{SiHa}$ cell DNA (fig 4) in which HPV 16 is integrated. DNA from HeLa cells, which contain integrated HPV 18 and human DNA extracted from a breast cancer, did not hybridise with the HPV 16 probe (data not shown).

\section{NISH TYPE 3 SIGNAL AND EPISOMAL AND} INTEGRATED HPV

Cases 12 and 121 both showed a type 3 NISH signal (figs $1 \mathrm{C}$ and $\mathrm{D}$ ). On Southern analysis of case 12 (fig 5), episomal HPV 16 bands were present in all three lanes of HindIII, XhoI, and digested DNA. BamHI linearised most of the HPV DNA to the 7.9 kilobase band, suggesting the presence of episomal viral DNA. An offsized fragment of about 23.1 kilobases was also present, suggesting the presence of virus-host cell junction fragments and implying HPV integration as well.

A similar situation existed in case 121 (fig 5) with episomal bands in the HindIII, XhoI, and uncut lanes in addition to bands at and smaller than 4.4 kilobases after $B a m H I$ digestion. This suggested HPV integration as well as the presence of episomal viral DNA. In this case, however, the bulk of HPV DNA did not linearise to 7.9 kilobases. This may be due to the presence of HPV multimers containing deletions or duplications ${ }^{31} 32$ with resultant unpredictable off-sized fragments or an HPV 16 variant in which the episomal form lacks the BamHI restriction site. ${ }^{8}$ Alternatively, they may represent integrated sequences.

As cases 12 and 121 gave an episomal and integrated pattern by Southern blot analysis, 2dimensional gel electrophoresis (2-D gel) was used to separate episomal and integrated sequences further. The integrated HPV 16 fragments co-migrate with the curved pathway of cellular DNA, which was marked out on the gel with ultraviolet illumination before Southern blotting (data not shown). The circular episomal molecules in both cases 12 and 121 remain closer to the lane of the first dimension due to their slower electrophoretic mobility implying integration of HPV 16 into the human genome in cases 14, 135 (fig 3), and 137. This Southern blot pattern was found in all three

16 specific signal is present in high molecular weight DNA bands after digestion with both HindIII and XhoI. The resultant bands have electrophoretic mobilities that differ from each 
U B H X

$\mathrm{Kb}$

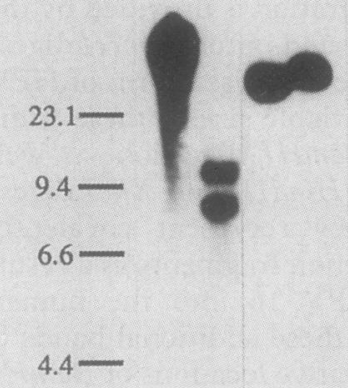

$\mathrm{Kb}$

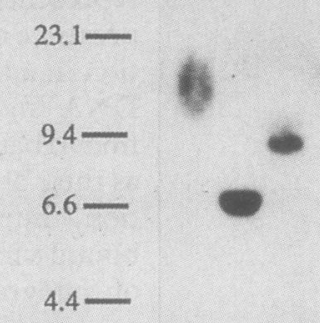

CaSki

$\mathrm{SiHa}$

Figure 4 Southern blot analysis of DNA from two cell lines derived from cervical cancer containing integrated HPV 16. These restriction patterns served as positive controls and are similar to those described in fig 3.

\section{$\mathrm{X}$ H B U}
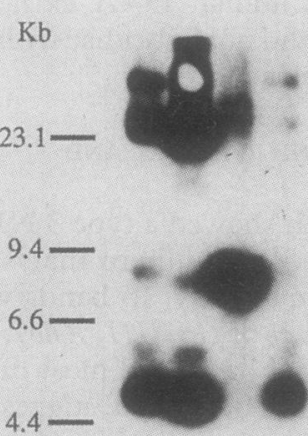

CASE 12
B $\mathrm{H} \quad \mathrm{X} \quad \mathrm{U}$

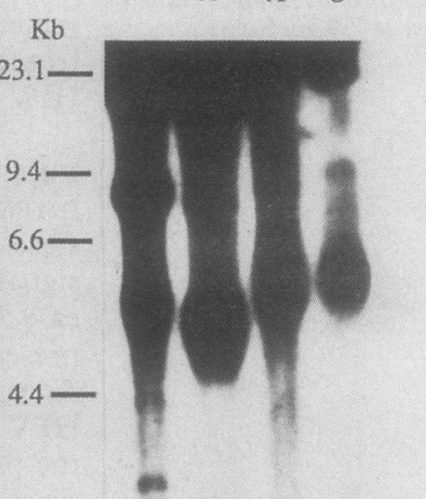

Figure 5 Southern blot analysis of DNA from case 12 (CIN3/HPV) and case 121 (squamous cell cancer), both of which contained an NISH signal type 3. Each lane comprised $10 \mu g$ DNA: undigested $(U)$, HindIII $(H), X h I(X)$ (both these enzymes do not cut HPV 16) and BamHI (B) (cuts HPV 16) once). Most of the bands in the uncut lane of case 12 linearise to 7.9 kilobases in the BamHI lane indicating predominantly episomal virus in this biopsy specimen. An off-sized band in this lane indicates the presence of integrated virus in addition. Case 121 is more complex in that two off-sized bands indicative of viral-cell junction fragments are present in addition to the 7.9 kilobase band after BamHI digestion. The smear in the uncut lane is also characteristic of integrated HPV DNA, which migrates with the bulk of the undigested genomic $D N A$.

compared with integrated DNA when the gel concentration is increased. ${ }^{283}$ The linear (7.9 kilobases) HPV 16 DNA which co-migrated with the cellular DNA is either integrated HPV DNA or more likely episomal viral particles linearised during the process of DNA extraction. This confirmed the presence of both episomal and integrated virus in cases 12 and 121 (fig 6) which showed type 1 and 2 NISH signals. The clinical diagnosis, NISH signal, and Southern blot patterns for each case studied are summarised in the table.

\section{Discussion}

HPV DNA is found in human epithelia in two forms, either individually or in combination: episomal (extrachromosomal) particles or integrated into the human genome. The integration of HPV 16 DNA has been shown directly on metaphase chromosomes from cervical carcinoma derived cell lines by in situ hybridisation ${ }^{17}$ and by cloning viral-cellular junction fragments from clinical cervical cancer. ${ }^{13}$ Southern analysis has led to the same conclusions in some cases of $\mathrm{CIN},{ }^{8-12} \mathrm{SCC}^{810-14}$ and cell lines derived from cervical cancers. ${ }^{67}$

This study explores the hypothesis that the NISH signal type is indicative of the physical state of the HPV genome in clinical samples. Using cryostat sections of frozen cervical tissue, NISH signals types 1 (diffuse throughout the nucleus), type 2 (punctuate/dot), and type 3 (combined 1 and 2) were shown in CIN (types 1 and 3) and SCC (types 2 and 3). The same cervical biopsy specimens were analysed by Southern blotting to investigate the physical state of the virus and to determine, by using another parameter, whether a type 1 signal represents episomal virus, type 2 signal represents integrated virus, and a type 3 signal represents the coexistence of both physical forms in the same lesion.

The presence of episomal HPV 16 was shown in six cases by the presence of forms 1-3 which linearise to 7.9 kilobases with $B a m H I$. The absence of additional off-sized bands in these biopsy specimens confirms that no integrated viral sequences was present in these lesions. Although small amounts of integrated viral DNA could, theoretically, be masked by the large excess of episomal sequences, this would only occur if the bands generated from the integrated sequences co-migrated with linear HPV 16. This is unlikely to occur other than by chance. The presence of high molecular weight bands in all six cases containing episomal virus probably represent oligomeric circular DNA arranged as catenates. This is not an unusual feature and has been noted in $72 \%$ of cases in a previous study. ${ }^{12}$ Therefore, an episomal pattern on Southern analysis correlates with NISH type 1 signal.

Integrated HPV was demonstrated in two ways: firstly, an altered migration of HPV 16 signal after digestion with two restriction enzymes that cut human DNA but not HPV 16 DNA, and secondly the presence of off-sized bands in BamHI digested DNA. As BamHI cuts HPV 16 DNA only once but also cuts genomic DNA, bands of size other than 7.9 kilobases are produced by digestion with this enzyme if integration has occurred at a site other than the BamHI restriction site. As viral breaks occur consistently in the E1/E2 open reading frames which do not contain the BamHI site, integration will almost invariably lead to the production of off-sized virus-cell junction fragments. The presence of a 7.9 kilobases band after BamHI digestion can be explained by the presence of integrated HPV 16 in the form of head-tail tandem repeats which has been demonstrated in CaSki cells. ${ }^{34}$ This pattern correlates with a NISH type 2 


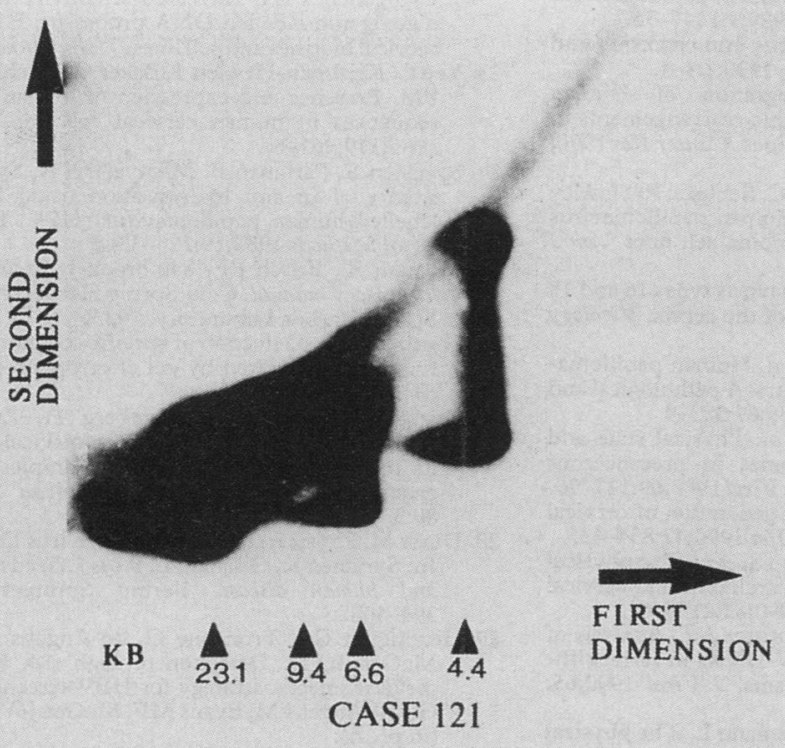

Figure 6 Analysis of HPV 16 DNA from case 121 by two-dimensional gel electrophoresis. DNA (10 $\mu \mathrm{g}$ ) was digested with HindIII (which has no cleavage site within the HPV 16 genome) and was separated in a $0.4 \%$ agarose gel in the first dimension, then rotated through $90^{\circ}$ and recast in a $0.8 \%$ gel for the second dimension. Distinct spots representing circular DNA are seen on the lower track in both cases; integrated HPV 16 is seen exclusively on the higher curved track comigrating with human genomic DNA. represents viral integration and permits further interpretation of previous data. ${ }^{18}$ In these studies all CIN2 that contained HPV DNA showed a diffuse type 1 signal. On the other hand, half the archival lesions defined morphologically as CIN3 with morphological evidence of HPV from patients from Britain and South Africa contained either a type 2 or type $3 \mathrm{NISH}$ signal. ${ }^{18}$ This indicates that these cervical biopsy specimens contained integrated virus without or with episomal forms, respectively. Similar conclusions have been arrived at by others using different methodologies. HPV DNA integration has been observed in CIN lesions $^{8-12}$ and has even been shown in mild cervical dysplasia. ${ }^{35}$ In one study $86 \%$ of HPV positive CIN lesions and $100 \%$ of HPV positive carcinoma in situ (CIS) and SCC contained HPV 16 in an integrated state. ${ }^{36}$ The co-existence of integrated and episomal forms of HPV has also been previously shown in CIN and $\operatorname{SCC}^{9}{ }^{13}$ and in cell lines derived from cervical cancers. ${ }^{67}$ The type 3 NISH signal pattern shows that these two physical states of HPV DNA may coexist in the same cell or in adjacent cells in the same lesion.

In another study we have shown a type 2 or 3 signal in $100 \%$ of HPV DNA positive SCC, indicating the integration of HPV in these tumours. ${ }^{19}$ A type 2 or 3 signal was also obtained with HPV 16, 18, and 33 in lesions from two different geographical regions, South Africa and Britain, implying integration of these three HPV types in SCC.

There is therefore a pattern regarding the physical state of the HPV DNA in CIN and SCC; that of episomes predominating in the early stages of $\mathrm{CIN}$, with integrated virus being detected more freqently in HPV positive high grade CIN and SCC. The latter may or may not contain episomes as well. This idea is not new. It has been proposed that the physical state of HPV DNA may reflect a progression towards the malignant phenotype ${ }^{932}$ and that higher grade CIN lesions may originate from a single cell clone in which viral integration had occurred. ${ }^{936}$ Therefore apart from the fact that lesion grade and HPV type-that is, 16 and 18-are established risk factors in clinical progression $^{37} 38$ the physical state of HPV DNA may also be relevant. The ability to determine the presence of integration in archival biopsy specimen by NISH will allow the importance of the physical state of HPV DNA and its role in progression or regression to be investigated further. This question could be addressed with retrospective or prospective studies where it has been shown that $56 \%$ of woman with HPV infection regressed spontaneously, $30 \%$ persisted, and a substantial proportion (14\%) progressed (some to CIS). ${ }^{39}$ on both conventional and two-dimension gels. The NISH type 3 signal therefore correlates with the presence of both episomal and integrated viral sequences. Southern analysis, however, cannot determine whether these two physical states of HPV coexist within the same cell or adjacent cells. ${ }^{9}$ This distinction is clearly made by NISH analysis (figs $1 \mathrm{C}$ and $\mathrm{D}$ ).

These results are further evidence in favour of the hypothesis that a punctuate NISH signal
1 DeVilliers E-M. Heterogeneity of the human papillomavirus group. J Virol 1989;63:4898-903.

2 Munoz N, Bosch FX. Current views on the role of human papillomavirus in the genesis of cervical neoplasia. Papillomavirus Rep 1991;2:57-9. 
3 Matlashewski G. The cell biology of human papillomavirus transformed cells. Anticancer Res 1989;9:1447-56.

4 McDougall JK. Human papillomavirus immortalising and transformation. Papillomavirus Rep 1990;1:1-4.

5 Popescu NC, Dipaolo JA. Integration of Human papillomavirus 16 DNA and genomic rearrangements in immortalised human keratinocyte lines. Cancer Res 1990; 50:1316-23.

6 Yee C, Krishman-Hewlatt I, Baker CC, Schlegel R, Howley PM. Presence and expression of Human papillomavirus sequences in human cervical carcinoma cell lines. $\mathrm{Am} \mathrm{J}$ Pathol 1985;119:361-6.

7 Pater MM, Pater A. Human papillomavirus types 16 and 18 sequences in carcinoma cells lines of the cervix. Virology 1985;145:313-18.

8 DiLuca D, Pilloti S, Stefanon B, et al. Human papillomavirus type $16 \mathrm{DNA}$ in genital tumours: A pathological and molecular analysis. $J$ Gen Virol 1986;67:583-9.

9 Lehn H, Villa LL, Marziona F, et al. Physical state and biological activity of HPV genomes in precancerous lesions of female genital tract. JGen Virol 1988;69:187-96.

10 Yoshikawa H. Virological studies on generation of cervical carcinomas. Acta Obstet Gynaecol Jpn 1990;42:834-43.

11 Fukushima M, Yamakawa Y, Shimano S, et al. The physical state of HPV 16 DNA in cervical carcinoma and cervical intraepithelial neoplasia. Cancer 1990;62:2155-61.

12 Cullen AP, Reid R, Campion M, Lorincz AT. Analysis of the physical state of different HPV DNAs in intraepithelial and invasive cervical neoplasms. $J$ Virol 1990;65: 606-12.

13 Dürst M, Kleinheitz A, Hotz M, Gissmann L. The physical state of HPV type 16 DNA in benign and malignant genital tumours. J Gen Virol 1985;66:1515-22

14 Lehn H, Sauer G. Organisation and expression of HPV type 16 genomes in human cervical carcinomas. In: Howley PM, Broker TR, eds. Papillomavirus: Molecular and clinical aspects. New York: Alan R Liss, 1985;32:57-65.

15 Vousden KH, Wrede D, Crook T. Human papillomavirus oncoprotein function: releasing the brakes on cell growth control. Papillomavirus Rep 1991;2:1-3.

16 Nagai N. Molecular biologic study on the carcinogenesis of Human papillomavirus in uterine cervical cancer and related lesions: analysis of HPV types 16, 18 E6/E7 gene mRNA (Japanese, English abstract). Acta Obstet Gynaecol Jpn 1990;42:823-33.

17 Mincheva A, Gissman L, Zur Hausen H. Chromosomal integration sites of human papillomavirus DNA in three cervical cancer cell lines mapped by the in situ hybridisation. Med Microbiol Immunol 1987; 176:245-56.

18 Cooper K, Herrington CS, Graham AK, Evans MF, McGee JO'D. In situ HPV genotyping of cervical intraepithelial neoplasia in South African and UK patients: Evidence for putative HPV integration. J Clin Pathol 1991;44:400-5.

19 Cooper K, Herrington CS, Graham AK, Evans MF, McGee JO'D. In situ evidence for HPV 16, 18, 33 integration in cervical squamous cell cancer in Britain and South Africa. J Clin Pathol 1991;44:406-9.

20 Coleman DV, Evans DMD. Biopsy pathology and cytology of the cervix. London: Chapman and Hall, 1988:199-227.

21 Herrington CS, Burns J, Graham AK, Bhatt B, McGee JO'D. Interphase cytogenetics using biotin and digoxigenin labelled probes I: relative sensitivity of both reported molecules for the detection of

22 Herrington CS, Graham AK, McGee JO'D. Interphase
Cytogenetics III: Increased sensitivity and flexibility of digoxigenin labelled DNA probes for HPV detection in cervical biopsies and cell lines. J Clin Pathol 1991;44:33-8.

23 Yee C, Krishnan-Hewlett I, Baker CC, Schlegel R, Howley PM. Presence and expression of human papillomavirus sequences in human cervical cell lines. Am J Pathol sequences in hum $1985 ; 119: 361-6$.

24 Syrjänen S, Partanen P, Mäntyajärvi R, Syrjänen K. Sensitivity of in situ hydridisation using biotin and $35 \mathrm{~S}$ labelled human papillomavirus (HPV) DNA probes. $J$ Virol Methods 1988;19:225-38.

25 Maniatis T, Frisch EF, Sambrook J. Molecular cloning, a laboratory manual. Cold Spring Harbor, New York: Cold Spring Harbor Laboratory, 1983.

26 Southern EM. Detection of specific sequences among DNA fragments separated by gel electrophoresis. $J$ Molecular Biol 1975;98:503-17.

27 Dürst $M$, Gissman $L$, Ikenberg $H$, Zur Hausen $H$. A papillomavirus DNA from a cervical carcinoma and A papilomavirus DNA from a cervical carcinoma and geographical regions. Proc Natl Acad Sci USA 1983;
80:3812-5.

28 Dürst M. Physical state of papillomavirus DNA in tumours. In: Syrjänen K, Gissman L, Koss LG, eds. Papillomavirus and human disease. Berlin: Springer-Verlag, 1987: $394-408$.

29 Herrington CS, Troncone G, de Angelis M, Evans MF, McGee JO'D. Detection of high risk HPV in routine cervical smears: strategy for HPV screening. Herrington CS, de Angelis M, Evans MF, McGee JO'D. J Clin Pathol (in press).

30 Meanwell CA, Cox MF, Blackledge G, Maitland NJ. HPV 16 DNA in normal and malignant cervical epithelium: Implications for the aetiology and behaviour of cervical neoplasia. Lancet 1987;i:703-7.

31 Choo KB, Cheung WF, Liew LN, Lee HH, Han SH Presence of catenated HPV type 16 episomes in cervical carcinoma cell line. J Virol 1989;63:782-9.

32 Diluca D, Monini P, Rotola A, Savioli A, Cassai E. Episomal HPV isolated from a cervical carcinoma presents a partial duplication of the early region Virus Res 1989; 14:49-56.

33 Johnson PH, Grossman LI. Electrophoresis of DNA in agarose gels. Optimising separation of conformational isomers of double and single stranded DNAs. Biochemistry 1977;16:4217-25.

34 Baker CC, Phelps WC, Lindgren V, Braun MJ, Gonda MA Howley PM. Structural and transcriptional analysis of Human papillomavirus 16 sequences in cervical carcinoma cell lines. $J$ Virol 1987;61:962-71.

35 Shimoda K, Lancaster WD. Integration of HPV DNA sequences in mild cervical dysplasia. Cancer Cell 1987 5:349-57.

36 Shirasawa H, Tomita Y, Kubota K, et al. Detection of HPV type 16 DNA and evidence for integration into the cell 37 Kataja V, Syriänen $K$, asia. J Gen Virol 1986;67:2011-5. follow up of cervical tuman papillo et al. Prospective follow up of cervical Human papillomavirus infections: colposcopic data. Eur J Epidemiol 1989:5 cytological and

colposcopic data. Eur J Epidemiol 1989;5:1-7.

up of syrazn $K$, Syrjanen S, et al. Prospective follow up of genital HPV infections: life table analysis of HPV typing data. Eur J Epidemiol 1990;6:9-14

39 Syrjänen KJ. Natural history of genital HPV infections. Papillomavirus Rep 1990;1:1-4. 